\title{
Biosorption of diazinon by a pre-treated alimentary industrial waste: equilibrium and kinetic modeling
}

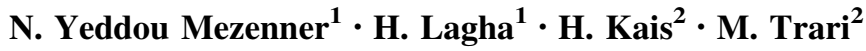

Received: 16 September 2016/ Accepted: 11 April 2017/Published online: 22 April 2017

(c) The Author(s) 2017. This article is an open access publication

\begin{abstract}
This study explores the feasibility of pre-treated coffee waste (PCW) as biosorbent for the removal of diazinon. The effect of the pesticide concentration (6-20 mg L $\left.{ }^{-1}\right)$, contact time, adsorbent dose $\left(0.2-1.2 \mathrm{~g} \mathrm{~L}^{-1}\right)$, solution $\mathrm{pH}$ (3-11.5), temperature $\left(15-40{ }^{\circ} \mathrm{C}\right)$ and co-existing inorganic ions $\left(\mathrm{H}_{2} \mathrm{PO}_{4}{ }^{-}\right.$, $\mathrm{NO}_{3}{ }^{-}$) on the diazinon biosorption over PCW is investigated. The experimental results indicate an optimal $\mathrm{pH}$ of 7.3 for the diazinon elimination on PCW $\left(1 \mathrm{~g} \mathrm{~L}^{-1}\right)$. The Langmuir model describes well the isotherm data with a high regression coefficient $\left(R^{2}>0.990\right)$ and a maximum monolayer biosorption capacity of $18.52 \mathrm{mg} \mathrm{g}^{-1}$ at $15{ }^{\circ} \mathrm{C}$. It is also observed that the intra-particle diffusion is not the rate-controlling step. A comparison is evaluated between the pseudo-second-order and intra-particle diffusion kinetic models; the experimental data are well fitted by the pseudosecond-order kinetic model. The biosorption capacity decreases with increasing temperature for a diazinon concentration of $10 \mathrm{mg} \mathrm{L}^{-1}$. The negative enthalpy $\Delta H^{\circ}$ $(-63.57 \mathrm{~kJ} / \mathrm{mol})$ indicates that the diazinon biosorption onto PCW is exothermic. Under optimal conditions, the biosorption reaches $95 \%$ after $90 \mathrm{~min}$. The removal efficiency decreases from 95 to 65.67 and $48.9 \%$ for the diazinon alone and in the presence of $\mathrm{NO}_{3}{ }^{-}$and $\mathrm{H}_{2} \mathrm{PO}_{4}{ }^{-}$ (100 $\mathrm{mg} \mathrm{L}^{-1}$ ), respectively.
\end{abstract}

M. Trari

solarchemistry@gmail.com

1 Laboratory of Chemical Engineering, Faculty of Mechanical and Chemical Engineering, USTHB, P.O. Box 32, 16111 Algiers, Algeria

2 Laboratory of Storage and Valorization of Renewable Energies, Faculty of Chemistry, USTHB, P.O. Box 32, Al Alia, 16111 Algiers, Algeria
Keywords Biosorption · Diazinon · Pesticide $\cdot$ Pre-treated coffee waste

\section{Introduction}

Among newly developed pesticides, organophosphorous compounds are most commonly used. Diazinon $(O, O$-diethyl $O$-[6-methyl-2-(1-methylethyl)-4- pyrimidinyl] phosphorothioate) is an organo-phosphorus insecticide classified by the World Health Organization (WHO) as "moderately hazardous" belonging to Class II. It is an organophosphate insecticide formerly employed for the fleas control, but remains toxic for the aquatic organisms at concentration as low as $350 \mathrm{ng} \mathrm{L}^{-1}$ ( $\mathrm{Li}$ et al. 2002) while fetal human doses were found to be extremely high in the range (90-445 $\mathrm{mg} \mathrm{kg}^{-1}$ ) (Zhang and Pehkonen 1999). Toxic effects of diazinon are attributed to its inhibition for the enzyme acetylcholinesterase (Shemer and Linden 2006). High diazinon residues were found in urban wastewaters and effluents from sewage treatment plants (Bailey et al. 2000; Li et al. 2002); hence, it is necessary to reduce its concentration before landfills. In this respect, several techniques are used for the pesticides removal such as advanced oxidation processes (Zhang and Pehkonen 1999), aerobic degradation (Nandagopal and Antony 2015), nanofiltration membranes (Mehta et al. 2017), ozonation (Shemer and Linden 2006) and biosorption (El Bakouri et al. 2009). However, the biosorption remains one of the most used techniques (Cortina et al. 2003) and has proven its effectiveness in the elimination of organic pollutants in aqueous medium (Zhang and Pehkonen 1999).

Suitable adsorbents must possess high removal efficiencies with economical, ecological and technological advantages. In this regard, activated carbons are currently 
favored because they can efficiently remove pesticides, organic compounds and metal ions. However, the high cost of activated carbons and their production are limiting factors, leading us to use inexpensive raw materials as adsorbents. Therefore, there is a need for the development of low-cost materials which adsorb organic pollutants. Natural biosorbents such as wood bark, peat, fly ash (Shemer and Linden 2006), acid-treated date stones (El Bakouri et al. 2009) are available in large quantities and may have a great potential in the water treatment. The utilization of an abundant residual biomass, namely the apricot stone, as a raw material for activated carbons gives an additional economical interest to the technical studies.

In this paper, we report the biosorption of diazinon onto pre-treated coffee waste (PCW). Several sets of experiments are conducted to determine the influence of biosorbent dose, initial diazinon concentration, temperature, solution $\mathrm{pH}$ as well as the effect of some anions on the diazinon biosorption. Equilibrium and kinetic analysis were conducted to determine the factors controlling the adsorption rate, the optimization of various parameters and to find out the possibility of using this material as low-cost adsorbent for pesticide removal.

\section{Materials and methods}

Waste coffee is obtained from industrial coffee production; it is thoroughly washed with deionised water and dried at $50{ }^{\circ} \mathrm{C}$ for $24 \mathrm{~h}$. Then, it is oxidized with $\mathrm{NaOCl}$ solution $(1 \%)$ in order to remove the organic matter (Yeddou and Bensmaili 2006). The powder is washed, dried and screened through a set of sieves to get geometrical size in the range $(50-210 \mu \mathrm{m})$. The chemical composition of PCW determined by X-ray fluorescence (XRF) using Horiba equipment is given in Table 1. The sample is mounted on a piece of metal, coated with $\sim 60 \mathrm{~nm}$ thickness of gold and observed by scanning electron microscopy (SEM, JEOL, JSM-6360LV).

The biosorbate is the diazinon which is a commercial pesticide $\left(\mathrm{C}_{12} \mathrm{H}_{21} \mathrm{~N}_{2} \mathrm{O}_{3} \mathrm{PS}\right.$, Fig. 1). All chemicals are of analytical reagent grade used without any further purification. The solutions are prepared from distilled water and the initial $\mathrm{pH}$ of the solution is adjusted with $\mathrm{NaOH}$ and $\mathrm{HCl}$ solutions.

\section{Kinetic studies}

PCW $\left(1 \mathrm{~g} \mathrm{~L}^{-1}\right)$ is mixed with $100 \mathrm{~mL}$ of the diazinon concentration $\left(6-20 \mathrm{mg} \mathrm{L}^{-1}\right)$ in conical flasks. The initial $\mathrm{pH}$ is adjusted at $\sim 7$ before mixing the adsorbent solution. The flasks are covered with aluminum foil and agitated on a shaker at constant temperature. The aliquots are withdrawn and separated from the biosorbent by centrifugation $(10,000 \mathrm{rpm}$,
Table 1 Chemical components of pre-treated coffee waste

\begin{tabular}{ll}
\hline Component & $\%$ \\
\hline $\mathrm{Na}_{2} \mathrm{O}$ & 0.4 \\
$\mathrm{MgO}$ & 0.419 \\
$\mathrm{Al}_{2} \mathrm{O}_{3}$ & 0.11 \\
$\mathrm{SiO}_{2}$ & 0.299 \\
$\mathrm{P}_{2} \mathrm{O}_{5}$ & 0.289 \\
$\mathrm{SO}_{3}$ & 0.031 \\
$\mathrm{~K}_{2} \mathrm{O}$ & 0.019 \\
$\mathrm{CaO}$ & 3.19 \\
$\mathrm{ZnO}$ & 0.014 \\
$\mathrm{Sr}$ & 0.026 \\
$\mathrm{Cl}$ & 7.995 \\
$\mathrm{~V}$ olatile matter & 84.607 \\
\hline
\end{tabular}

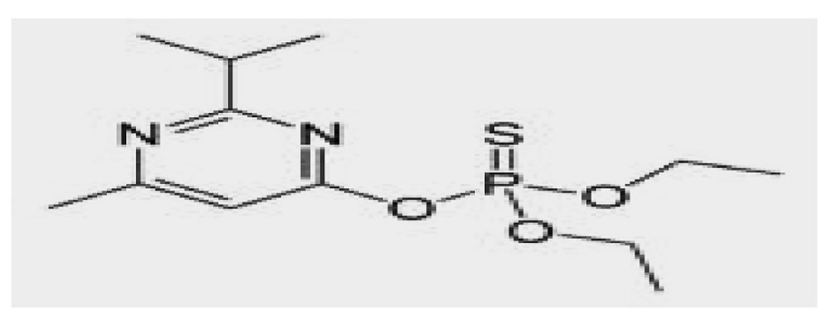

Fig. 1 Chemical formula of the diazinon

$20 \mathrm{~min}$ ); their concentrations are determined using UV-Vis spectrophotometer (Shimadzu 1800, $\lambda_{\max }=248 \mathrm{~nm}$ ).

\section{Equilibrium studies}

\section{Effect of adsorbent dose}

The equilibrium data are obtained by addition of $(0.02-0.12 \mathrm{~g})$ of PCW into a series of conical flasks filled with $100 \mathrm{~mL}$ of diazinon solution $\left(10 \mathrm{mg} \mathrm{L}^{-1}\right)$. The flasks covered with aluminum foil are placed in a thermostatic shaker for $2 \mathrm{~h}$ at $15{ }^{\circ} \mathrm{C}$.

\section{Effect of $p H$ and initial concentration}

The biosorption tests are performed with different diazinon solutions over the $\mathrm{pH}$ range (3-11.5) on PCW (100 mg). The experiments are carried out by addition of $0.1 \mathrm{~g}$ of PCW to $100 \mathrm{~mL}$ of solutions over the concentrations range (3-20 mg L $\left.{ }^{-1}, \mathrm{pH} 7.3\right)$.

\section{Effect of temperature}

The thermal variation of the biosorption is investigated in the range $\left(15-40{ }^{\circ} \mathrm{C}\right)$. The flasks containing $0.1 \mathrm{~g}$ of diazinon $(\mathrm{pH} 7.3)$ are placed in a thermostatic shaker at 15, 25, 30 and 
$40{ }^{\circ} \mathrm{C}$. The removal efficiency $(E)$ of the diazinon degradation on $\mathrm{PCW}$, the biosorption capacity $(q)$ and the distribution ratio $\left(K_{\mathrm{d}}\right)$ are calculated from the relations:

$E=\frac{C_{0}-C_{\mathrm{f}}}{C_{0}}$,

$q=\frac{V\left(C_{0}-C_{\mathrm{f}}\right)}{m}$,

$K_{\mathrm{d}}=\frac{\text { amount } \text { of diazinon on adsorbent }}{\text { amount of diazinon in solution }}$,

where $C_{\mathrm{o}}$ and $C_{\mathrm{f}}$ are the initial and final concentrations (mg L ${ }^{-1}$ ), respectively, $V$ is the volume of the solution (L) and $m$ is the weight of the adsorbent $(\mathrm{g})$.

\section{Results and discussion}

\section{Effect of the initial concentration on the diazinon biosorption}

The effect of initial concentration of diazinon $\left(C_{\mathrm{o}}\right)$ on the biosorption rate by PCW is shown in Fig. 2. The quantity

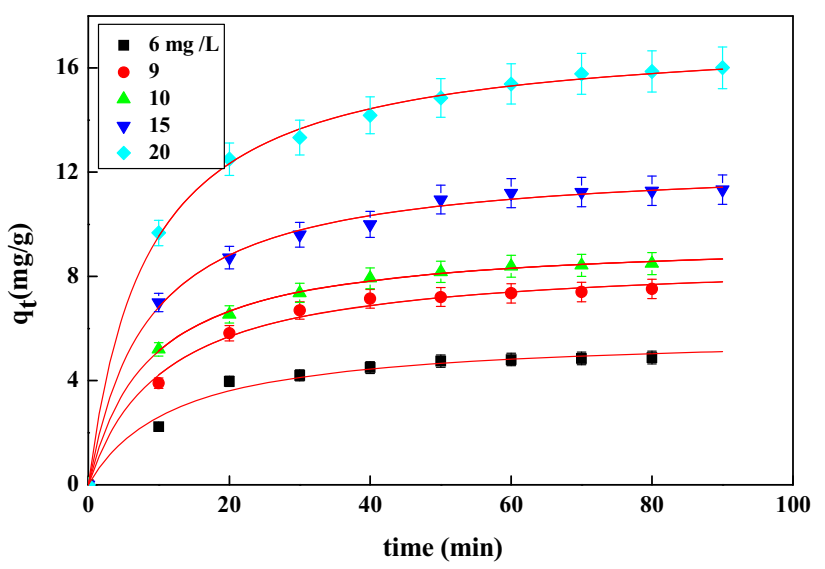

Fig. 2 Biosorption on pre-treated coffee waste at different diazinon concentrations

Fig. 3 Diazinon biosorption on pre-treated coffee waste at different temperatures of biosorbed pesticide increases with time for all concentrations. As the concentration $\mathrm{C}_{\mathrm{o}}$ increases from 6 to $20 \mathrm{mg} \mathrm{L}^{-1}$, the loading capacity of PCW increases from 4.81 to $15.39 \mathrm{mg} \mathrm{g}^{-1}$ during the first hour, attributed to the increased biosorbate quantity. The rapid pesticide uptake for the first $10 \mathrm{~min}$ is due to the occurrence of molecule transfer ascribed to diazinon-biosorbent interactions with negligible interference solute-solute. The enhanced biosorption may also be due to the fact that initially, the sites on the PCW surface are vacant and the solute concentration gradient is high. The extent of diazinon uptake decreases over the contact time, because of the gradual decrease in the number of the surface sites. The remaining vacant sites become difficult to be reached due to repulsive forces between the solute molecules on the surface and bulk phase, thus leading to saturation (Al-Qodah et al. 2007; Ramanaiah et al. 2007). When the biosorption involves a surface reaction, the initial step is rapid.

\section{Effect of temperature}

The thermal effect on the diazinon biosorption on PCW (Fig. 3) shows that the uptake capacity $\left(q_{\mathrm{e}}\right)$ decreases with raising temperature, indicating an exothermic biosorption, which is inhibited at high temperatures. An explanation of the decreased biosorption with temperature may be attributed to low number of polar groups of carbons (i.e., carboxylic oxygen).

\section{Effect of pH on the biosorption equilibrium}

The biosorption is strongly dependent on $\mathrm{pH}$ through the functional groups of the biosorbent. Figure 4 shows that the removal efficiency of diazinon increases with $\mathrm{pH}$, an abrupt variation is found in the $\mathrm{pH}$ range (3.0-7.3). The maximum biosorption $\left(9.5 \mathrm{mg} \mathrm{g}^{-1}\right)$ is obtained at $\mathrm{pH} 7.3$ and decreases for higher $\mathrm{pHs}$ due to the ionic form of the diazinon (aromatic structure, polar groups) in solution and the electrical charge of PCW. The weak removal at high
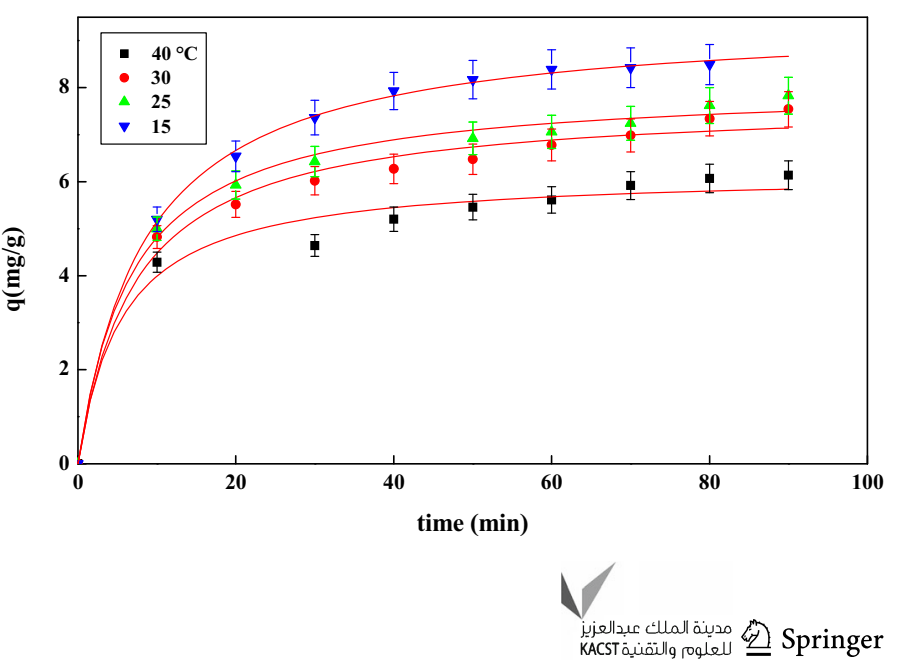


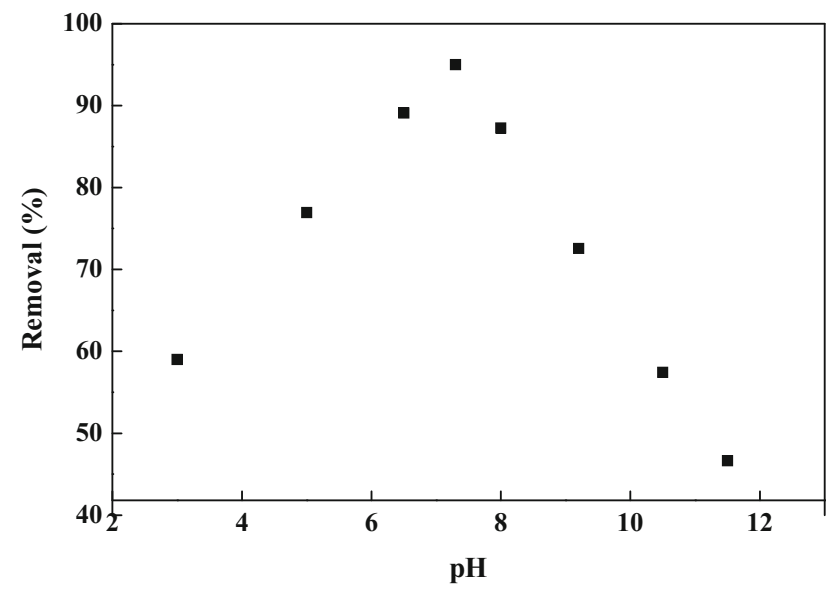

Fig. 4 Diazinon biosorption on pre-treated coffee waste (PCW) at different $\mathrm{pHs}$

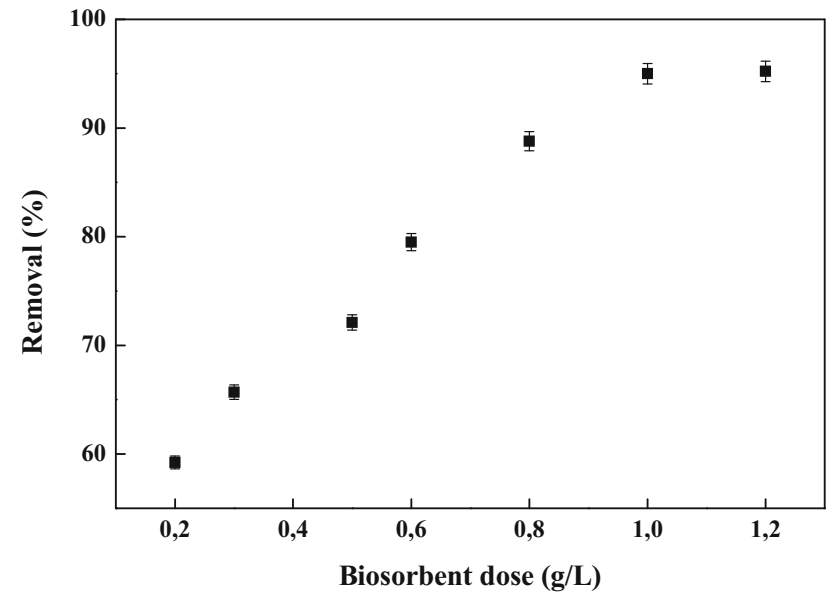

Fig. 5 Effect of the biosorbent dose on the diazinon removal

$(>7.3)$ and low pHs $(<5)$ may be due to the diazinon hydrolysis. So, the $\mathrm{pH}$ appears to be a key factor affecting the diazinon biosorption. The optimal $\mathrm{pH}$ leads to a high surface potential, allowing a better biosorption.

\section{Effect of the biosorbent dose}

To determine the biosorbent quantity for a maximal removal of diazinon, the effect of the PCW dose on the biosorption equilibrium is illustrated in Fig. 5 which shows the uptake of diazinon for five doses over the range $\left(0.2-1.2 \mathrm{~g} \mathrm{~L}^{-1}\right)$. For a concentration of $10 \mathrm{mg} \mathrm{L}^{-1}, \mathrm{PCW}$ dose of $1 \mathrm{~g} \mathrm{~L}^{-1}$ is found to be optimal. This is probably due to the resistance to the mass transfer of the pesticide from the bulk liquid to the PCW surface, which becomes important at high biosorbent doses; this optimal dose is used for further experiments.

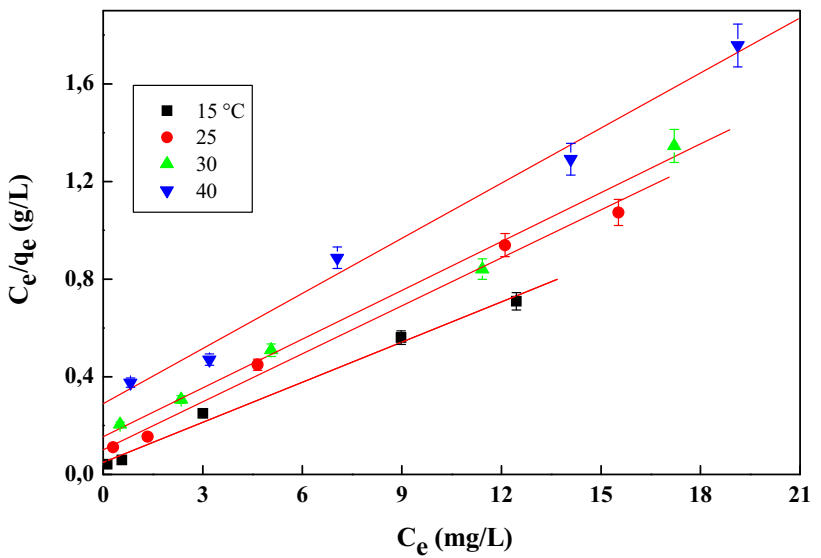

Fig. 6 The Langmuir adsorption isotherms for pre-treated coffee waste at various temperatures

\section{Batch isotherm studies}

The capacity of PCW to absorb the diazinon is determined by measuring the equilibrium isotherms to describe the interaction adsorbate $\left(10 \mathrm{mg} \mathrm{L}^{-1}\right) /$ adsorbent $\left(1 \mathrm{~g} \mathrm{~L}^{-1}\right)$ at $\mathrm{pH} \sim 7.3$. Thus, a correlation of the equilibrium data by either theoretical or empirical equations is essential for the practical operations to optimize the design of the biosorption system; so it is important to establish the most appropriate correlation for the equilibrium curves. The isotherm data are analyzed using the commonly used equilibrium models, namely the Langmuir and Freundlich ones (Hamdaoui et al. 2008; Akar et al. 2009; Al-Qodah et al. 2007). The mathematical expressions are, respectively, given by

$q_{\mathrm{e}}=q_{\max } \frac{b C_{e}}{1+b C_{\mathrm{e}}}$,

the linearized form gives

$C_{\mathrm{e}} / q_{\mathrm{e}}=1 /\left(q_{\mathrm{m}} b\right)+C_{\mathrm{e}} / q_{\mathrm{m}}$,

$q_{\mathrm{e}}=K_{\mathrm{f}} \cdot C_{\mathrm{e}}^{1 / n}$,

whose linearized form is

$\ln q_{\mathrm{e}}=\ln K f+(1 / n) \ln C_{\mathrm{e}}$,

where $q_{\max }\left(\mathrm{mg} \mathrm{g}^{-1}\right)$ is the maximum amount of diazinon per unit weight of PCW, to form a complete monolayer on the surface and $b\left(\mathrm{~L} \mathrm{mg}^{-1}\right)$ is a constant related to the affinity of the binding sites, determined from the linear plot of $C_{\mathrm{e}} / q_{\mathrm{e}}$ versus $C_{\mathrm{e}}$. The characteristic constant $K_{\mathrm{f}}$ (mg L $\mathrm{L}^{-1 / n} \mathrm{~g}^{-1} \mathrm{~L}^{1 / n}$ ) and the dimensionless $n$ are determined from the linearized form of Eq. (5).

Figures 6 and 7 show the plots of linearized forms; the best-fitted parameters deduced from Eqs. (4) and (5) by the linear regression analysis are listed in Table 2, along with 


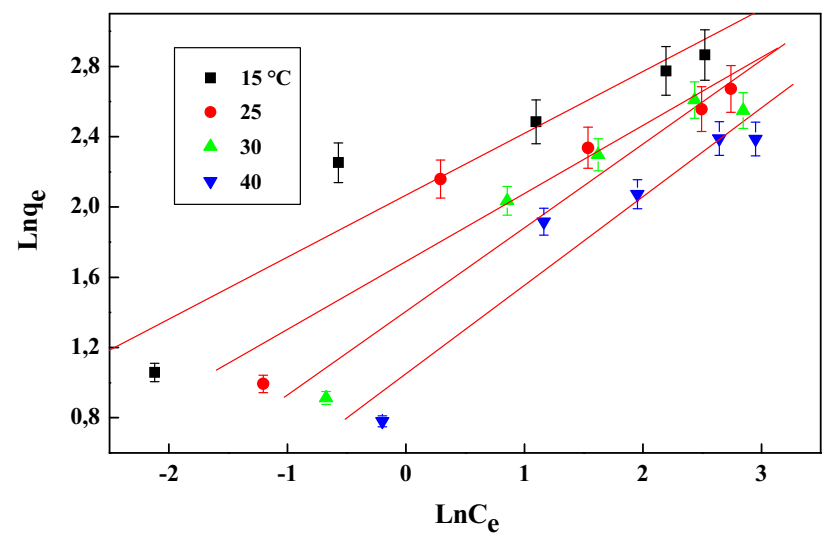

Fig. 7 The Freundlich adsorption isotherm for pre-treated coffee waste at various temperatures

the regression coefficients $\left(R^{2}\right)$, which provide a measurement of the model fitness. The $\mathrm{R}^{2}$ coefficients of the Freundlich model are lower $\left(0.891 \leq R^{2} \leq 0.925\right)$ than those of Langmuir $\left(0.990 \leq R^{2} \leq 0.992\right)$. The $n$ values are greater than unity $(1.980<n<2.840$; Table 2$)$, indicating that the diazinon is favorably adsorbed on PCW. The constants $K_{\mathrm{f}}$ and $n$ are obtained at $15{ }^{\circ} \mathrm{C}$ and this implies that the binding capacity reaches the maximal value and the affinity PCW/diazinon is higher at that temperature. The high regression coefficient shows that the Langmuir model is the most suitable for describing the biosorption over the studied concentrations range and suggests that some homogeneity in the PCW surface or inside the pores plays a role in the biosorption. The surface of PCW grains is regular with homogeneous porous structure as shown in the SEM image (Fig. 8). Similar results were obtained by Azouaou et al. (Azouaou et al. 2010) for the $\mathrm{Cd}^{2+}$ adsorption by untreated coffee residue. The maximum capacity $q_{\max }$, determined from the Langmuir isotherm, was $18.52 \mathrm{mg} \mathrm{L}^{-1}$ at $15{ }^{\circ} \mathrm{C}$ and the large $b$ value $(=1.102)$ implies a strong interaction diazinon/PCW. The essential feature of the Langmuir isotherm can be expressed by a

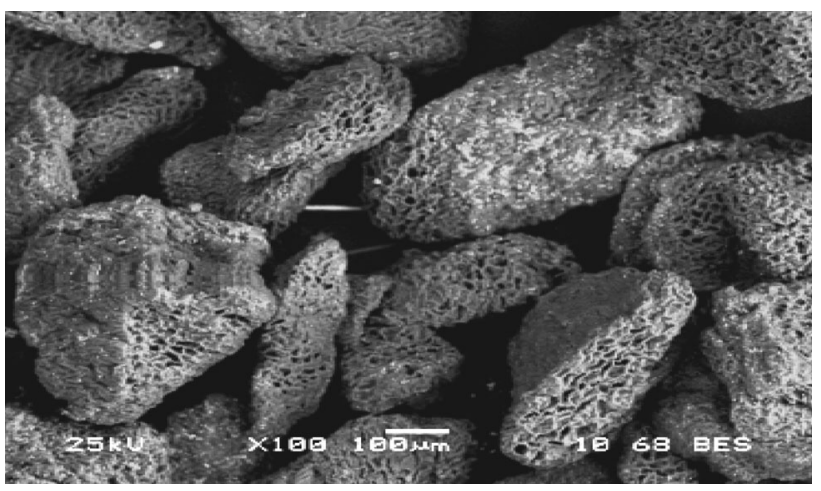

Fig. 8 SEM image of pre-treated coffee waste (PCW)

dimensionless separation factor $\left(R_{\mathrm{L}}\right)$, defined by (Chatzopoulos et al. 1993):

$R_{L}=\frac{1}{1+b C_{0}}$.

The $R_{\mathrm{L}}$ value indicates the isotherm type: unfavorable $\left(R_{\mathrm{L}}>1\right)$, linear $\left(R_{\mathrm{L}}=1\right)$, irreversible $\left(R_{\mathrm{L}}=0\right)$ or favorable $\left(0<R_{\mathrm{L}}<1\right)$; the separation factor $\left(R_{\mathrm{L}}\right)$ increases from 0.083 to 0.27 as the temperature increases from 15 to $40{ }^{\circ} \mathrm{C}$ (Table 2).

\section{Biosorption kinetics}

The biosorption rate gives information for the designing batch biosorption systems. To clarify the kinetics of diazinon biosorption onto PCW, the pseudo-second-order and intra-particle models are applied to the experimental data. The derived rate constants together with the regression coefficient $R^{2}$ are gathered in Tables 3 and 4 . The effects of temperature and initial concentration $\left(C_{\mathrm{o}}\right)$ on the biosorption kinetics are also examined. The pseudo-second-order model gives the best fit with the kinetic data for the diazinon-PCW systems; all regression coefficients are high ( $>0.99$, Table 3$)$. In the case of the intra-particle model, the regression coefficients are between 0.812 and
Table 2 Isotherm constants for diazinon adsorption onto pretreated coffee waste

\begin{tabular}{|c|c|c|c|c|}
\hline & \multicolumn{4}{|c|}{ Temperature } \\
\hline & $15^{\circ} \mathrm{C}$ & $25^{\circ} \mathrm{C}$ & $30^{\circ} \mathrm{C}$ & $40^{\circ} \mathrm{C}$ \\
\hline \multicolumn{5}{|l|}{ Freundlich } \\
\hline$n$ & 2.84 & 2.58 & 2.10 & 1.98 \\
\hline$K_{\mathrm{f}}\left(\mathrm{mg} \mathrm{L}^{-1 / n} \mathrm{~g}^{-1} \mathrm{~L}^{1 / n}\right)$ & 7.89 & 5.41 & 4.07 & 2.85 \\
\hline$r^{2}$ & 0.891 & 0.890 & 0.926 & 0.925 \\
\hline \multicolumn{5}{|l|}{ Langmuir } \\
\hline$q_{\max }(\mathrm{mg} / \mathrm{g})$ & 18.52 & 15.38 & 15.15 & 13.33 \\
\hline$b(\mathrm{~L} / \mathrm{mg})$ & 1.102 & 0.643 & 0.428 & 0.259 \\
\hline$r^{2}$ & 0.992 & 0.990 & 0.990 & 0.990 \\
\hline
\end{tabular}


Table 3 Parameters for the pseudo-second-order equation

\begin{tabular}{|c|c|c|c|c|}
\hline & $K_{2}(\mathrm{~g} / \mathrm{mg} \min ) \times 10^{3}$ & $Q_{\mathrm{e}}(\mathrm{mg} / \mathrm{g})$ & $\mathrm{H}(\mathrm{mg} / \mathrm{g} \min )$ & $R^{2}$ \\
\hline \multicolumn{5}{|c|}{$\mathrm{C}_{\mathrm{o}}(\mathrm{mg} / \mathrm{L})$} \\
\hline 6 & 15.5 & 5.6818 & 0.50 & 0.993 \\
\hline 9 & 11.28 & 8.9525 & 0.904 & 0.996 \\
\hline 10 & 12.0 & 9.4339 & 1.153 & 0.999 \\
\hline 15 & 9.566 & 12.5 & 1.494 & 0.998 \\
\hline 20 & 6.31 & 17.86 & 2.012 & 0.999 \\
\hline \multicolumn{5}{|c|}{$T\left({ }^{\circ} \mathrm{C}\right)$} \\
\hline 15 & 12.9 & 9.4339 & 1.153 & 0.999 \\
\hline 25 & 14.05 & 8.333 & 0.975 & 0.995 \\
\hline 30 & 12.26 & 8.13 & 0.8103 & 0.993 \\
\hline 40 & 14.45 & 6.7567 & 0.660 & 0.991 \\
\hline
\end{tabular}

Table 4 Parameters for intra-particle diffusion model

\begin{tabular}{|c|c|c|c|c|}
\hline & $\mathrm{K}_{\mathrm{i}}\left(\mathrm{mg} / \mathrm{g} \min ^{1 / 2}\right)$ & $R^{2}$ & $\operatorname{Di}\left(\mathrm{cm}^{2} / \mathrm{s}\right) \times 10^{7}$ & $T_{1 / 2}(\min )$ \\
\hline \multicolumn{5}{|c|}{$C_{\mathrm{o}}(\mathrm{mg} / \mathrm{L})$} \\
\hline 6 & 0.450 & 0.813 & 5.33 & 11.34 \\
\hline 9 & 0.558 & 0.812 & 6.11 & 9.90 \\
\hline 10 & 0.619 & 0.928 & 7.39 & 8.17 \\
\hline 15 & 0.821 & 0.957 & 7.23 & 8.37 \\
\hline 20 & 1.108 & 0.949 & 6.81 & 8.87 \\
\hline \multicolumn{5}{|c|}{$T\left({ }^{\circ} \mathrm{C}\right)$} \\
\hline 15 & 0.619 & 0.928 & 7.39 & 8.17 \\
\hline 25 & 0.409 & 0.954 & 7.08 & 8.54 \\
\hline 30 & 0.404 & 0.986 & 6.03 & 10.03 \\
\hline 40 & 0.321 & 0.950 & 5.91 & 10.24 \\
\hline
\end{tabular}

0.986 (Table 4), suggesting the inapplicability of the model for the diazinon biosorption on PCW.

\section{Pseudo-second-order model}

Based on the equilibrium biosorption, the pseudo-secondorder kinetic equation is expressed by the relation (Hamdaoui et al. 2008):

$\frac{t}{q_{\mathrm{t}}}=\frac{1}{K_{2} q_{\mathrm{e}}^{2}}+\frac{t}{q_{\mathrm{e}}}$,

where $K_{2}$ is the rate constant $(\mathrm{g} / \mathrm{mg} \mathrm{min})$ :

$h=K_{2} q_{\mathrm{e}}^{2}$,

$h$ is the initial biosorption rate ( $\mathrm{mg} / \mathrm{g} \mathrm{min})$. According to Ho (Ho 2006), the advantage of this model is that there is no need to know the equilibrium capacity from the experiments, since it can be easily calculated. In addition, the initial biosorption rate can be obtained from the model. Reported studies (Walker et al. 2003) showed that the

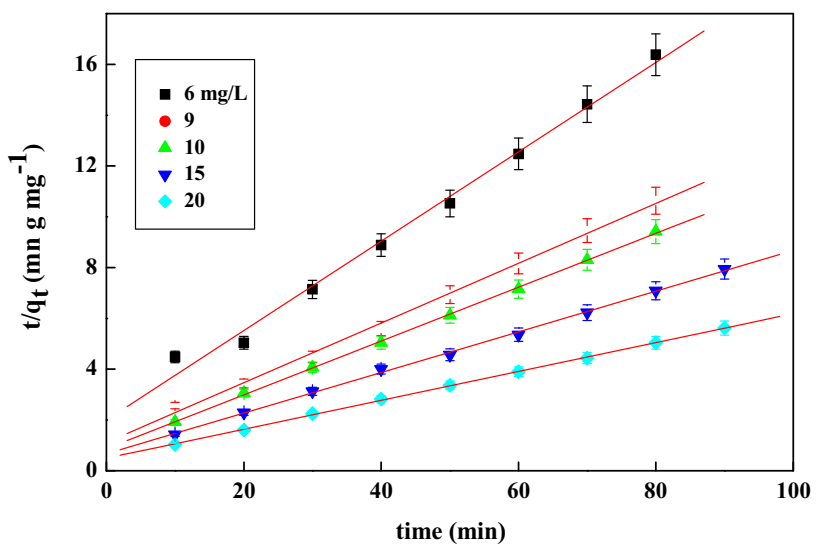

Fig. 9 Pseudo-second biosorption kinetics of preatreated coffee waste at various diazinon concentrations

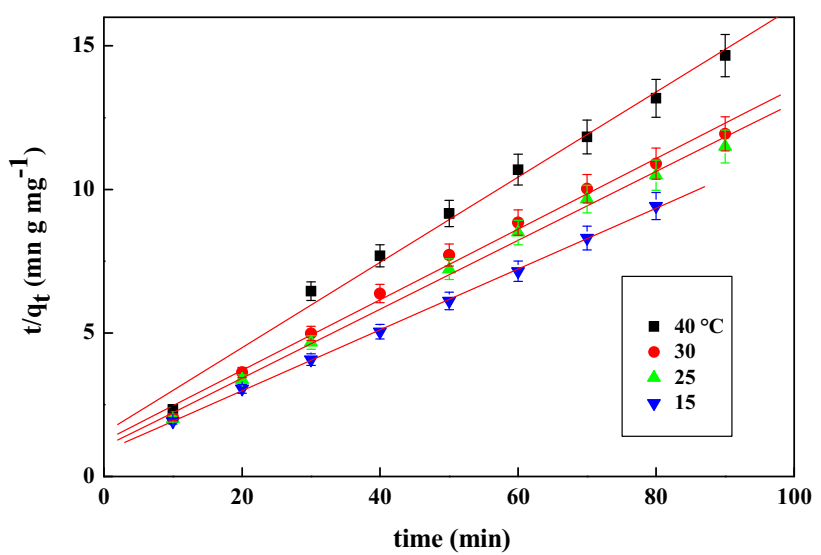

Fig. 10 Pseudo-second biosorption kinetics of pre-treated coffee waste at different temperatures

pseudo-second-order rate equation gives reasonably a good fit of the experimental data over the entire fractional approach to equilibrium and is extensively employed in the biosorption kinetics (Weber and Morris 1963). The application of the linear forms of the pseudo-secondorder kinetic model on our experimental data is presented in Fig. 9 (for different concentrations) and Fig. 10 (different temperatures); the constants $K_{2}$ and $q_{\mathrm{e}}$ are determined from the intercept and slope of the straight line obtained by plotting $t / q_{\mathrm{t}}$ versus $t$, respectively. It can also be observed that the equilibrium biosorption capacity $q_{\mathrm{e}}$ increases with increasing the diazinon concentration $C_{\mathrm{o}}$, from 6 to $20 \mathrm{mg} \mathrm{L}^{-1}$ (Table 3). In addition, it has been found that the biosorption rate $h$ decreases with $C_{\mathrm{o}}$ according to the relation:

$h=-0.102 C_{o}-0.022 \quad\left(R^{2}=0.976\right)$,

$q_{\mathrm{e}}$ can be expressed as a function of $\mathrm{C}_{\mathrm{o}}$ by the following relation: 
$q_{e}=0.824 C_{o}+0.995 \quad\left(R^{2}=0.984\right)$.

Substituting the values of $q_{\mathrm{e}}$ and $h$ from Eqs. 9 and 10 into Eqs. 7 and 8, one can derive the rate law for the pseudo-second-order and the relationship of $q_{\mathrm{t}}, t$ and $C_{\mathrm{o}}$ :

$q_{\mathrm{t}}=\frac{0.08405 C_{0}^{2} t-0.08336 C_{0} t-0.0219 t}{0.102 C_{0} t-0.022 t+0,824 C_{0}+0.995}$.

Equation (11) is used to derive the amount of biosorbed diazinon at any time and for any concentration. The variations of $t / q_{\mathrm{t}}$ versus $t$ at various temperatures of the diazinon solution $\left(10 \mathrm{mg} \mathrm{L}^{-1}\right)$ confirm the validity of the pseudo-second-order model. The parameters $K_{2}, h$ and $q_{\mathrm{e}}$ at different temperatures are calculated from Eqs. (12) and (13); the results (Table 3) reveal that the fitted biosorption capacity at equilibrium $q_{\mathrm{e}}$ decreases from $9.43 \mathrm{mg} \mathrm{g}^{-1}$ at $15^{\circ} \mathrm{C}$ to $6.75 \mathrm{mg} \mathrm{g}^{-1}$ at $40{ }^{\circ} \mathrm{C}$, while the initial biosorption rate, $h$, decreases with increasing temperature:

$$
\begin{array}{ll}
h=-0.021 T+1.456 & R^{2}=0.982, \\
q_{e}=-0.104 T+11.03 & R^{2}=0.980 .
\end{array}
$$

Substituting the values of $q_{\mathrm{e}}$ and $H$ from Eqs. (12) and (13) into Eqs. (7) and (8), one obtains the rate law for the pseudo-second-order and relationship of $\mathrm{q}_{\mathrm{t}}, \mathrm{t}$ and $\mathrm{T}$ :

$q_{\mathrm{t}}=\frac{0.00208 T^{2} t-0.372 T t+16.06 T t}{-0.02 T t+1.456 t-0.104 T+11.03}$.

The data of the diazinon biosorption (Figs. 9 and 10) confirm the validity of the pseudo-second-order model with $R^{2}$ coefficient between 0.974 and 0.986 . The confrontations of the experimental and predicted results are shown in Fig. 11a for the concentrations and Fig. 11b for the temperatures.

\section{Intra-particle diffusion}

The diffusion mechanism and the kinetic results are also analyzed by the intra-particle diffusion model developed by Weber and Morris (1963), and McKay and Poots (1980) where the initial rate of intra-particle diffusion is calculated by linearization of Eq. (15)

$q_{t}=K_{\mathrm{p}} t^{1 / 2}+C$

$C\left(\mathrm{mg} \mathrm{g}^{-1}\right)$ is a constant related to the thickness of the boundary layer, attributed to the instantaneous utilization of the most readily available adsorbing sites on the adsorbent surface.

The diffusion rate constant $K_{\mathrm{p}}\left(\mathrm{mg} / \mathrm{g} \min ^{1 / 2}\right)$ is determined from the slopes of the linear plots of $q_{\mathrm{t}}$ versus $t^{1 / 2}$ for various diazinon concentrations and temperatures (Fig. 12). The $R^{2}$ coefficients are between 0.812 and 0.986 (Table 4). $K_{\mathrm{p}}$ increases from 0.45 to $1.108 \mathrm{mg} \mathrm{g}^{-1} \mathrm{~min}^{1 / 2}$ with
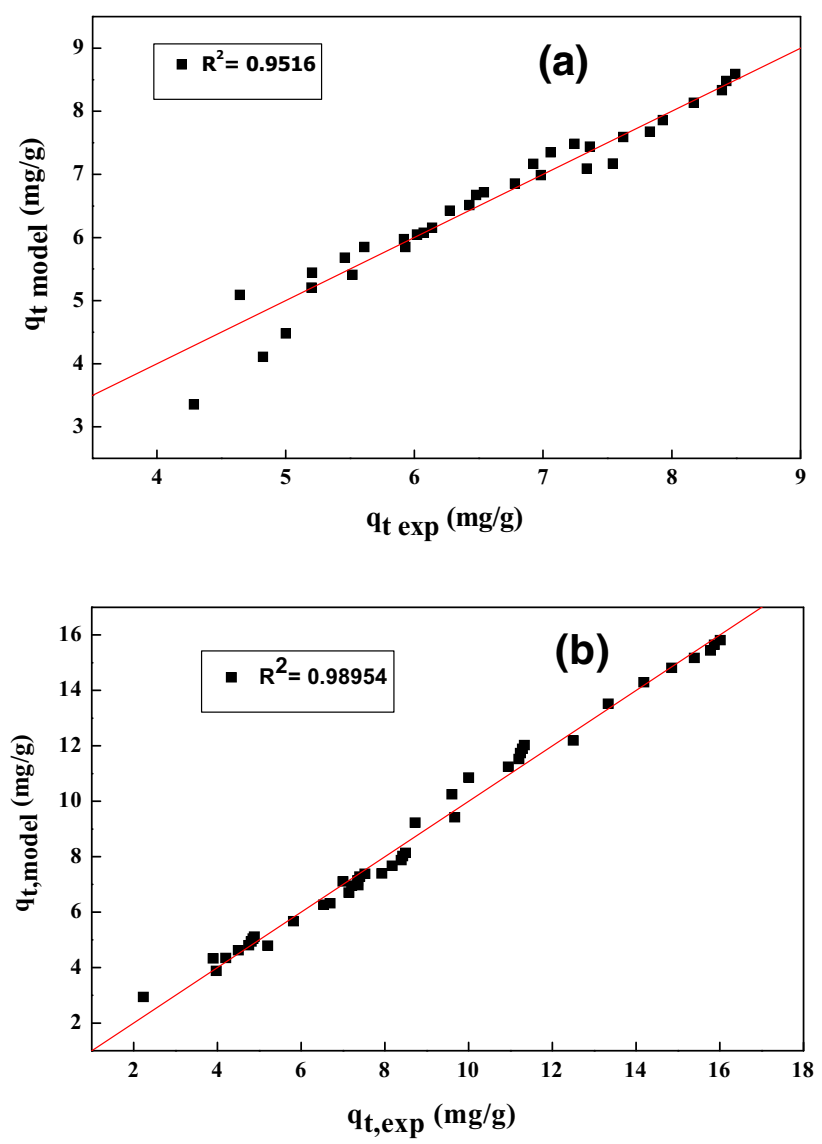

Fig. 11 Experimental versus predicted confrontations of the biosorption capacity for the diazinon-PCE for different concentrations (a) and different temperatures (b)

increasing the concentration $C_{\mathrm{o}}$ from 6 to $20 \mathrm{mg} \mathrm{L}^{-1}$ and this can be explained by the increased driving force which reduces the diffusion of diazinon in the boundary layer and enhances the diffusion in the solid. In addition, raising the temperature reduces the pore diffusion in the biosorbent particles, resulting in a reduction in the intra-particle diffusion rate (Moussa and Trari 2015). The corresponding constants $K_{\mathrm{p}}$ vary from 0.619 to $0.321 \mathrm{mg} / \mathrm{g} \mathrm{min}^{1 / 2}$ in the range $\left(15-40{ }^{\circ} \mathrm{C}\right)$ (Table 4). The straight lines do not pass by the origin (Fig. 12), implying that the intra-particle diffusion is not the only rate-controlling step. In addition, the diffusion coefficients $\left(D_{\mathrm{p}}, \mathrm{cm}^{2} / \mathrm{s}\right)$ for the intra-particle transport of diazinon in the pores of biosorbent particles have been calculated from Eqs. (16) and (17) (Shemer and Karl 2006),

$D_{\mathrm{P}}=\frac{0.03 r_{0}^{2}}{t_{1 / 2}}$,

$t_{\frac{1}{2}}=\frac{1}{k_{2} q_{\mathrm{e}}}$,

where $t_{1 / 2}$ is the time for half-biosorption of diazinon; the average radius $\left(r_{\mathrm{o}}\right)$ of the adsorbent particle $(\mathrm{cm})$ is found to be $11 \times 10^{-3} \mathrm{~cm}$, assuming spherical particles. With 


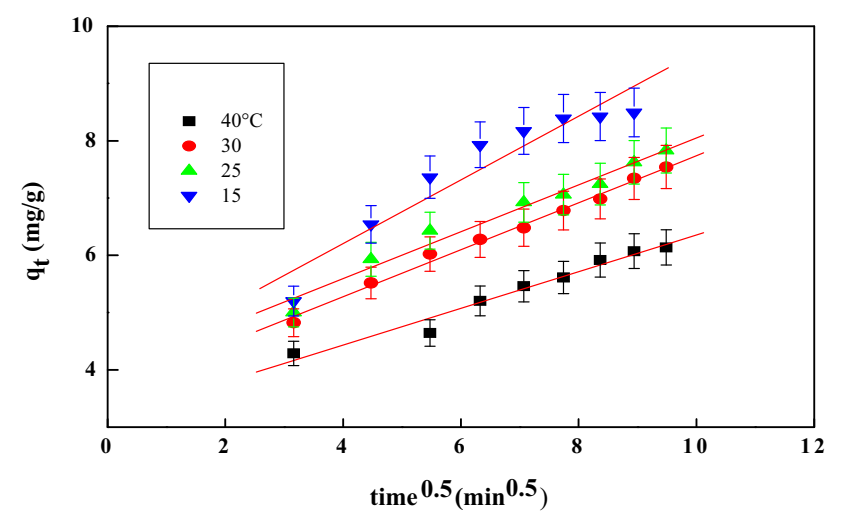

(a)

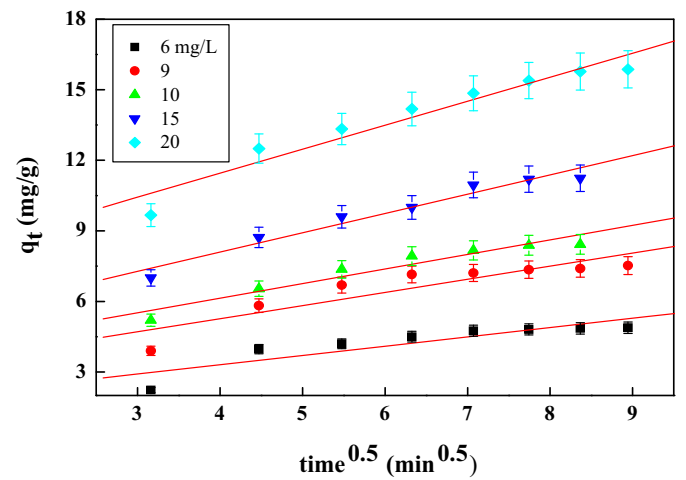

(b)

Fig. 12 Plot of intra-particle diffusion modeling of diazinon onto PCW at various temperatures (a) and concentrations (b)

increasing the diazinon concentration $C_{\mathrm{o}}$ from 6 to $10 \mathrm{mg} \mathrm{L}^{-1}$, the coefficient $D_{\mathrm{p}}$ increases from $5.33 \times 10^{-7}$ to $7.39 \times 10^{-7} \mathrm{~cm}^{2} / \mathrm{s}$ and then decreases to $6.81 \times 10^{-7} \mathrm{~cm}^{2} /$ $\mathrm{s}$ in the concentration range $\left(10-20 \mathrm{mg} \mathrm{L}^{-1}\right)$. This concentration dependence of the diffusivity agrees with the literature (Moussa and Trari 2015). It is also observed that $D_{\mathrm{p}}$ decreases as the temperature increases from 15 to $40{ }^{\circ} \mathrm{C}$. The $D_{\mathrm{p}}$ values (Table 4 ) are within the magnitudes reported in the literature (Hamdaoui et al. 2008), and confirm that the intra-particle diffusion is not the only ratecontrolling step.

\section{Thermodynamic study}

The type of the biosorption can be determined through the thermodynamic functions, i.e., the free energy $\left(\Delta G^{\circ}\right)$, the enthalpy $\left(\Delta H^{\circ}\right)$ and entropy $\left(\Delta S^{\circ}\right)$ for the diazinon biosorption on PCW:

$\Delta G^{\circ}=-R T \ln K_{\mathrm{d}}$,

$\ln K_{\mathrm{d}}=-\frac{\Delta H^{\circ}}{R T}+\frac{\Delta S^{\circ}}{R}$,

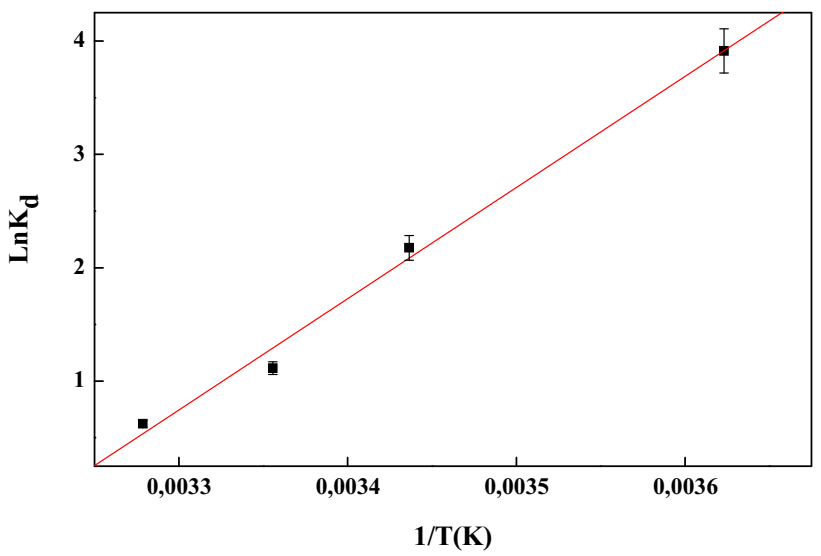

Fig. 13 The thermal variation of $K_{\mathrm{d}}$ of diazinon adsorption onto PCW

Table 5 Thermodynamic parameters of the diazinon biosorption

\begin{tabular}{llll}
\hline $\begin{array}{l}\text { Temperature } \\
\left({ }^{\circ} \mathrm{C}\right)\end{array}$ & $-\Delta G^{\circ}(\mathrm{kJ} / \mathrm{mol})$ & $-\Delta S^{\circ}(\mathrm{kJ} / \mathrm{mol})$ & $\Delta H^{\circ}(\mathrm{kJ} / \mathrm{mol})$ \\
\hline 10 & 6.73 & 57.01 & -63.57 \\
15 & 4.62 & 58.99 & \\
20 & 2.97 & 59.58 & \\
30 & 1.96 & 61.96 & \\
\hline
\end{tabular}

where $T$ is the absolute temperature and $R$ is the universal gas constant. Figure 13 shows a linear relationship between the logarithm of rate constant and $T^{-1}$. The values of $\Delta H^{\circ}$ $\left(-63.57 \mathrm{~kJ} \mathrm{~mol}^{-1}\right)$ and $\Delta S^{\circ}\left(-0.198 \mathrm{~kJ} \mathrm{~mol}^{-1}\right)$ are determined from the slope and intercept of the plot of $\ln K_{\mathrm{d}}$ versus $T^{-1}$. The negative entropy reflects the decreased randomness at the solid/solution interface during the diazinon biosorption while the negative free energy $\left(\Delta G^{\circ}\right)$ (Eq. 12) indicates a feasible biosorption onto PCW. $\Delta G^{\circ}$ increases from -6.73 to $-1.96 \mathrm{~kJ} / \mathrm{mol}$ in the range (10-40 ${ }^{\circ} \mathrm{C}$, Table 5), thus suggesting more biosorbed diazinon at low temperature. The negative enthalpy indicates an exothermic process controlled by chemical mechanism $\left(>40 \mathrm{~kJ} \mathrm{~mol}^{-1}\right)$ where the interaction diazinon-PCW is mainly electrostatic (Coulombic interactions). The heat of the biosorption involves relatively strong intermolecular forces and mainly electrostatic interaction as well as hydrogen bond.

\section{Effect of co-existing inorganic ions}

The presence of inorganic ions was found to influence the kinetics and mechanism of the catalytic degradation of organic pollutant (Muhamad 2010). The uptake of pesticides from wastewaters is different from that of a simple pesticide in solution. Indeed, the real effluents 
contain not only organic contaminants but also many inorganic ions and heavy metals which change the ionic strength of the solution and affect the biosorbent capacity. Therefore, the diazinon biosorption onto PCW (10 $\mathrm{mg} \mathrm{L}^{-1}$ ) was carried out in the presence of two inorganic ions $\left(\mathrm{NaH}_{2} \mathrm{PO}_{4}\right.$ and $\left.\mathrm{NaNO}_{3}\right)$. Hence, the effect of $\mathrm{H}_{2} \mathrm{PO}_{4}{ }^{-}$and $\mathrm{NO}_{3}{ }^{-}$on the biosorption is investigated by varying the concentrations of $\mathrm{H}_{2} \mathrm{PO}_{4}{ }^{-}$and $\mathrm{NO}_{3}{ }^{-}$over the range $\left(50-100 \mathrm{mg} \mathrm{L}^{-1}\right)$ at $\mathrm{pH} 7.3$ and $15^{\circ} \mathrm{C}$. The surface coverage by inorganic ions is competitive with the adsorption of the pesticides which is directly related to their occupation fraction and consequently has a negative impact on the biosorption. It is worth mentioning that the $\mathrm{pH}$ does not change significantly; it remains nearly constant with neutral ion $\mathrm{NO}_{3}{ }^{-}$while it increased to $\mathrm{pH} \sim 10$. So with $\mathrm{H}_{3} \mathrm{PO}_{4}$, the $\mathrm{pH}$ increase also accounts for the decreased degradation.

The result shows that $\mathrm{H}_{2} \mathrm{PO}_{4}{ }^{-}$is a more powerful inhibitor than $\mathrm{NO}_{3}{ }^{-}$. As the ion concentration increases, the removal efficiency of diazinon decreases from 86 to $48.9 \%$ and from 94.56 to $65.67 \%$, respectively, with $\mathrm{H}_{2} \mathrm{PO}_{4}{ }^{-}$and $\mathrm{NO}_{3}{ }^{-}$. Such behavior is due to the interaction between the biosorbent surface and added solutes which may compete for the active sites and consequently block the diazinon biosorption. In addition, the inhibition of these ions is probably due to the existence of repulsive forces anion/diazinon.

\section{Conclusion}

Pre-treated coffee waste showed a good biosorption for the diazinon and, therefore, can serve as a low-cost alternative for costly activated carbon. Diazinon is classified as a hazardous insecticide and its biosorption on pre-treated coffee waste is of great potential. The effect of the insecticide concentration, contact time, adsorbent dose, solution $\mathrm{pH}$, temperature and inorganic ions on the biosorption was studied. The biosorption increases until pH 7.3 and then decreases at higher pHs. The Langmuir isotherm model gave the best fitting of the experimental data. Batch studies showed that the pseudo-second-order kinetic model can adequately predict the diazinon biosorption. Moreover, it is observed that the intra-particle diffusion is not the rate-controlling step. The kinetic parameters were of the same order of magnitude of those reported in the literature. The thermodynamic study showed a spontaneous and exothermic biosorption onto PCW with chemical diazinon-PCW electrostatic interactions. The diazinon removal efficiency was lower in the presence of inorganic ions $\mathrm{NO}_{3}{ }^{-}$and $\mathrm{H}_{2} \mathrm{PO}_{4}{ }^{-}$and decreased with increasing their concentrations because of their competitive coverage on the PCW surface.
Acknowledgements The authors thank Dr. M. Fedailaine for his technical assistance. The financial support was provided by the Faculty of mechanical and Engineering Processes (USTHB, Algiers).

Open Access This article is distributed under the terms of the Creative Commons Attribution 4.0 International License (http:// creativecommons.org/licenses/by/4.0/), which permits unrestricted use, distribution, and reproduction in any medium, provided you give appropriate credit to the original author(s) and the source, provide a link to the Creative Commons license, and indicate if changes were made.

\section{References}

Akar T, Anilan B, Gorgulu A, Akar ST (2009) Assessment of cationic dye biosorption characteristics of untreated and non-conventional biomass: Pyracantha coccinea berries. J Hazard Mater 168:1302-1309

Al-Qodah Z, Shawaqfeh AT, Lafi WK (2007) Adsorption of pesticides from aqueous solutions using oil shale ash. Desalination 208:294-305

Azouaou N, Sadaoui Z, Djaafri A, Mokaddem H (2010) Adsorption of cadmium from aqueous solution onto untreated coffee grounds: equilibrium, kinetics and thermodynamics. J Hazard Mater 184:126-134

Bailey H, Deanovic L, Reyes E, Kimball T, Larson K, Cortright K, Connor V, Hinton D (2000) Diazinon and chlorpyrifos in urban waterways in northern California, USA. Environ Toxicol Chem 19:82-87

Chatzopoulos D, Varma A, Irvine RL (1993) Activated carbon adsorption and desorption of toluene in the aqueous phase. AIChE J 39:2027-2041

Cortina JL, Warshawsky A, Kahana N, Kampel V, Sampaio CH, Kautzmann RM (2003) Kinetics of goldcyanide extraction using ion-exchange resins containing piperazine functionality. React Funct Polym 54:25-35

El Bakouri H, Usero J, Morillo J, Rojas R, Ouassini A (2009) Drin pesticides removal from aqueous solutions using acid-treated date stones. Biores Tech 100:2676-2684

Hamdaoui O, Saoudi F, Chiha M, Naffrechoux E (2008) Sorption of malachite green by a novel sorbent, dead leaves of plane tree: equilibrium and kinetic modeling. Chem Eng J 143:73-84

Ho Y (2006) Review of second-order models for adsorption systems. J Hazard Mater B136:681-689

Li PCH, Swanson EJ, Gobas FAPC (2002) Diazinon and its degradation products in agricultural water courses in British Columbia. Bull Environ Contam Toxicol 69:59-65

Mckay G, Poots VJP (1980) Kinetics and diffusion process in colour removal from effluent using wood as an adsorbent. J Chem Technol Biotechnol 30:279-292

Mehta R, Brahmbhatt H, Mukherjee M, Bhattacharya A (2017) Tuning separation behavior of tailor-made thin film poly(piperazine-amide) composite membranes for pesticides and salts from water. Desalination 404:280-290

Moussa M, Trari M (2015) Kinetic, equilibrium and thermodynamic study on the removal of Congo Red from aqueous solutions by adsorption onto apricot stone. Process Saf Environ Prot 98:424-436

Muhamad SG (2010) Kinetic studies of catalytic photodegradation of chlorpyrifos insecticide in various natural waters. Arab J Chem 3:127-133

Nandagopal MSG, Antony R (2015) Experimental exploration on degradation of orange G 16 an azo dye by novel 
Pseudoalteromonas sp. and its enzyme activity. Arab J Sci Eng 40:1005-1013

Ramanaiah SV, Venkata Mohan S, Sarma PN (2007) Adsorptive removal of fluoride from aqueous phase using waste algal fungus (Pleurotus ostreatus). J Hazard Mater 141:465-474

Shemer H, Karl G (2006) Degradation and by-product formation of diazinon in water during $\mathrm{UV}$ and $\mathrm{UV} / \mathrm{H}_{2} \mathrm{O}_{2}$ treatment. J Hazard Mater B136:553-559

Shemer H, Linden KG (2006) Degradation and by-product formation of diazinon in water during $\mathrm{UV}$ and $\mathrm{UV} / \mathrm{H}_{2} \mathrm{O}_{2}$ treatment. J. Hazmat 136:553-559
Walker GM, Hansen L, Hanna JA, Allen SJ (2003) Kinetics of a reactive dye adsorption onto dolomic sorbents. Water Res 37:2081-2089

Weber WJ, Morris JC (1963) Kinetics of adsorption on carbon from solution. J Sanit Eng Div Am Soc Civ Eng 89:31-60

Yeddou N, Bensmaili A (2006) Equilibrium and kinetic modelling of methylene blue biosorption by pretreated dead streptomyces rimosus: effect of temperature. Chem Eng J 119:121-125

Zhang Q, Pehkonen SO (1999) Oxidation of diazinon by aqueous chlorine: kinetics, mechanisms, and product studies. J Agric Food Chem 47:1760-1766 